\title{
O ensino da Clínica Ampliada para ingressantes do curso de Odontologia: um relato de experiência
}

\author{
Fernanda Campos de Almeida Carrer*; Maristela Honório Cayetano**; Mariana Gabriel***; Andrea \\ Carla Franchini Melani****; Julie Silva Martins*****; Henrique Rizzo******; Mariana Lopes******; \\ Thais Torralbo Lopez-Capp ${ }^{* * * * * * * ;}$ Dorival Pedroso da Silva*******; Maria Ercilia de \\ Araujo**********
}

* Professora Doutora, supervisora do estágio da Disciplina de Clínica Ampliada de Promoção de Saúde do Departamento de Odontologia Social, FOUSP

** Doutoranda em Odontologia Social, Departamento de Odontologia Social, FOUSP, Docente da Universidade Ibirapuera.

*** Pesquisadora do Departamento de Odontologia Social, FOUSP, Docente da Universidade Mogi das Cruzes

**** Douutora em Odontologia Social

***** Pesquisadora do Departamento de Odontologia Social, FOUSP

****** Mestrando, Departamento de Odontologia Social, FOUSP

******* Pesquisadora em Odontologia Forense, Departamento de Odontologia Social, FOUSP

******** Professor Livre Docente do Departamento de Cirurgia, Trauma e Prótese Maxilo Faciais da FOUSP, supervisor do estágio da Disciplina de Clínica Ampliada de Promoção de Saúde Professora Titular, coordenadora do estágio da Disciplina de Clínica Ampliada de Promoção de Saúde do Departamento de Odontologia Social, FOUSP

Recebido em 22/03/2017. Aprovado em 30/12/2017.

\begin{abstract}
RESUMO
De acordo com as Diretrizes Curriculares Nacionais para os cursos de Odontologia, a formação do Cirurgião-dentista deve resultar em um profissional capaz de atender às necessidades de saúde bucal da população e estar em consonância com os princípios do Sistema Único de Saúde. Para tanto, o ensino da clínica deve extrapolar o ato operatório e ampliar seu escopo de prática. Neste sentido, desde 2006, a Faculdade de Odontologia da Universidade de São Paulo ministra aos estudantes do primeiro semestre de graduação a Disciplina denominada Clínica Ampliada de Promoção de Saúde (CAPS), que se propõe, desde o ingresso do estudante no curso superior, a romper com o paradigma da saúde como ausência de doença e apresentar a interface entre o biológico e o social neste processo, na perspectiva da ampliação da clínica e do cuidado integral. Este relato de experiência tem o objetivo de descrever a disciplina de CAPS, caracterizando as estratégias pedagógicas e sua relevância na inserção dos estudantes nos cenários de prática na atenção básica, bem como os métodos de avaliação implementados durante o ano. Espera-se que o modelo de Disciplina apresentado possa fomentar o debate e promover discussões dentro dos cursos de Odontologia, para que o mais precocemente possível, possamos discutir com os estudantes temas relacionados ao cuidado em saúde e à clínica ampliada.
\end{abstract}

Descritores: Educação Odontológica. Promoção de Saúde. Currículo. 


\section{INTRODUÇÃO}

O Sistema Único de Saúde (SUS) propõe uma visão ampliada do processo saúde doença, com reconhecimento da importância da determinação social para além do conceito reduzido e monocausal. A universidade, por sua vez, deve ser capaz de formar um profissional que domine as ferramentas adequadas e que reconheça as interfaces entre o biológico e o social no processo saúde doença, capacitando-o para que atinja o objetivo final de promover o cuidado. Este objetivo é, inclusive, um dos principais fatores que motivam os estudantes a buscar um curso da área da saúde ${ }^{1}$.

Para adequar a formação dos cursos de Odontologia às necessidades contemporâneas, em 2002, a Câmara de Educação Superior do Conselho Nacional de Educação instituiu as Diretrizes Curriculares Nacionais (DCN), que definem em seu artigo $3^{\circ}$ o perfil do egresso dos cursos de Odontologia, destacando as características desejaveis para esse profissional, dentre as quais salientamos a formação generalista, humanista, crítica e reflexiva ${ }^{2}$. No entanto, existe resistência por parte do corpo docente das universidades em incorporar as mudanças propostas pelas DCNs, sendo frequente relatos de desinteresse em novas práticas ou em compreender o processo saúde doença para além dos aspectos biológicos ${ }^{3}$.

As diretrizes da ABENO para definição de estágios curriculares supervisionados colocam que os estágios devem incluir vivências e práticas em situações reais, em contato com a realidade social e que permitam uma prática integral do cuidado em saúde. Para tanto, o curso deveria oferecer espaços de aprendizado, preparando este estudante para que, no contato com o território e com os serviços de saúde, possa exercer a Clínica Ampliada, de modo a reconhecer os determinantes sociais do processo saúde doença e interferir nesse processo de forma efetiva ${ }^{4}$.
De acordo com o framework proposto por Bozorgmher, o estudante é parte da força de trabalho da saúde (health workforce), que se refere a todas as pessoas engajadas em ações que, em primeira instância, procuram melhorar a saúde da população. Portanto, estudantes inseridos nos serviços de saúde devem ser considerados força de trabalho em saúde e devem se envolver com o processo de cuidado, se corresponsabilizando pelo que ocorre dentro do serviço de saúde". A literatura tem relatado nos últimos anos diversos trabalhos que apontam a importância de se adequar a formação em saúde à realidade local da população.

De Araujo (2006) ${ }^{5}$ alerta que a formação preconizada pelas DCN deve estar atrelada às necessidades de saúde bucal da população e inserida no paradigma dos princípios do SUS. Neste sentido, em 2006, a Faculdade de Odontologia da Universidade de São Paulo (FOUSP) realizou uma importante alteração na sua estrutura curricular, vigente desde 1982. Dentre as mudanças na estrutura do curso de Odontologia descreveremos a seguir a implementação de uma disciplina, denominada Clínica Ampliada de Promoção de Saúde (CAPS), que propõe, desde o ingresso do estudante no curso superior, romper com o paradigma da saúde como ausência de doença, apresentando o processo saúde doença, como um processo social, seguindo tendência mundial de formação de recursos humanos em saúde e utilizando metodologias de problematização ${ }^{6-9}$.

O ensino na área da saúde, a partir da determinação social, tem sido estudado ao redor do mundo e a CAPS tem seguido os pressupostos propostos por Bozorgmehr et al, 2011 ${ }^{10}$. Este modelo teórico é baseado nos Determinantes Sociais em Saúde (Social Determinats of Health - SDH) e é orientado na direção do conceito de Saúde para Todos (Health for All - HFA). O GHE é construído sobre 3 princípios subjacentes à 
HFA: 1) Health as a fundamental human right (saúde como um direto humano fundamental), 2) equity in health and solidarity in action (equidade em saúde e solidariedade em ação), 3) participation and accountability (participação e prestação de contas). De acordo com os autores, seguindo estes princípios, as intervenções educacionais devem ter relevância social e serem orientadas pelas necessidades da população.

Este relato de experiência tem o objetivo de descrever a disciplina de CAPS, caracterizando as estratégias pedagógicas e sua relevância na inserção dos estudantes nos cenários de prática na atenção básica, assim como os métodos de avaliação implementados.

\section{METODOLOGIA}

Trata-se de um estudo descritivo, do tipo relato de experiência, baseado em análises documentais dos roteiros de aula, cronogramas e ementa da disciplina. A CAPS foi criada em um contexto institucional no qual a FOUSP realizava sua reestruturação curricular, em consonância com as políticas indutoras do Ministério da Saúde e da Educação, tais como Pró-Saúde, e que fomentaram a revisão das matrizes curriculares dos cursos de saúde ${ }^{9}$. Durante os dez anos nos quais a disciplina tem sido ministrada, foi possível estruturar avanços que merecem ser contemplados por outros atores, de forma que relatar a experiência em detalhes poderia contribuir com o ensino em saúde.

$\mathrm{O}$ relato de experiência apresenta, inicialmente, os percursos pedagógicos da Disciplina, com ênfase na ementa e nos objetivos proposto desde sua criação, seguido pela descrição dos módulos e das estratégias pedagógicas aplicadas pelo corpo docente, com o cuidado de que todos os textos e teorias trabalhadas durante o ano com os estudantes sejam citados, a fim de que o leitor possa compreender as escolhas teóricas que embasam a CAPS.

\section{O RELATO DA EXPERIÊNCIA:}

\section{A Disciplina de Clínica Ampliada de Promoção de Saúde: Percursos pedagógicos}

Em um novo contexto de formação, que nos desafia para uma proposta de ensino aprendizagem na busca da construção compartilhada de saberes e práticas, a CAPS foi implementada no primeiro ano do curso de graduação da FOUSP. Sua proposta pedagógica convida o estudante a participar ativamente de sua formação, construindo seu conhecimento a partir de vivências nos serviços de atenção primária à saúde do SUS, com base na tríade ensino-serviço-comunidade ${ }^{11,12}$.

A Disciplina tem como objetivo auxiliar o estudante a ampliar seu olhar para além do técnico, do biológico e da assistência odontológica restrita ao consultório e ao cuidado individual, apresentando ao graduando a complexidade do processo saúde doença, favorecendo o desenvolvimento de competências que permitam uma prática assistencial pautada nos princípios da cidadania, no reconhecimento da autonomia dos usuários, na interação com a população e com a equipe de saúde, na busca de soluções para os problemas identificados e no envolvimento com os resultados da assistência.

Pretende-se oferecer ao estudante ferramentas que permitam reconhecer a história social da doença, iniciando sua compreensão sobre Estratégia de Saúde da Família (ESF) como modalidade de assistência à saúde; oferecer aos graduandos a oportunidade de ampliação dos cenários de ensino-aprendizagem e da duração da prática educacional na rede de serviços básicos de saúde; promover o desenvolvimento de habilidades e padrões de comportamento voltados para o envolvimento com os problemas de saúde da comunidade no plano individual e coletivo e na relação profissional/usuário baseada na alteridade e na responsabilidade social. 
A CAPS se propõe, desde a entrada do estudante no curso de Odontologia, a deslocar o eixo central do ensino do foco exclusivo na doença, incorporando a noção integralizadora do processo saúde doença e da promoção da saúde, com ênfase na atenção básica; favorecer a adoção de metodologias pedagógicas ativas e centradas nos estudantes, visando prepará-los para a autoeducação permanente num mundo de constante renovação da ciência; estimular o estudante a ter uma visão crítica da realidade, que perceba a importância social de um profissional da saúde capaz de tomar decisões que transformem a realidade para o benefício da população; por meio de atividades clínicas no território do entorno da FOUSP trabalhar e reforçar os conceitos abordados em sala de aula; estabelecer, de forma sistemática e autossustentável, protocolos de cooperação entre a
FOUSP, a Secretaria Municipal de Saúde via gestores municipais do SUS, a Secretaria de Estado de São Paulo, o Ministério da Saúde e o Ministério da Educação ${ }^{13}$.

A disciplina é ministrada, desde 2006, formando anualmente, nos períodos integral e noturno, 133 estudantes. Visando uma maior integração e aproveitamento pedagógico, a turma é dividida em pequenos grupos (de 20 a 25 estudantes), e cada grupo conta com um orientador (professor ou estudante de pós-graduação), um estudante de iniciação científica e um monitor (figura 1B). A disciplina é organizada por módulos, como descrito no fluxograma da figura $1 \mathrm{~A}$ e a cada módulo planeja-se e pactua-se com os estudantes um conjunto de elementos pedagógicos finais que devem ser apreendidos no referido módulo, porém em um movimento cíclico e indissociável (tabela1).

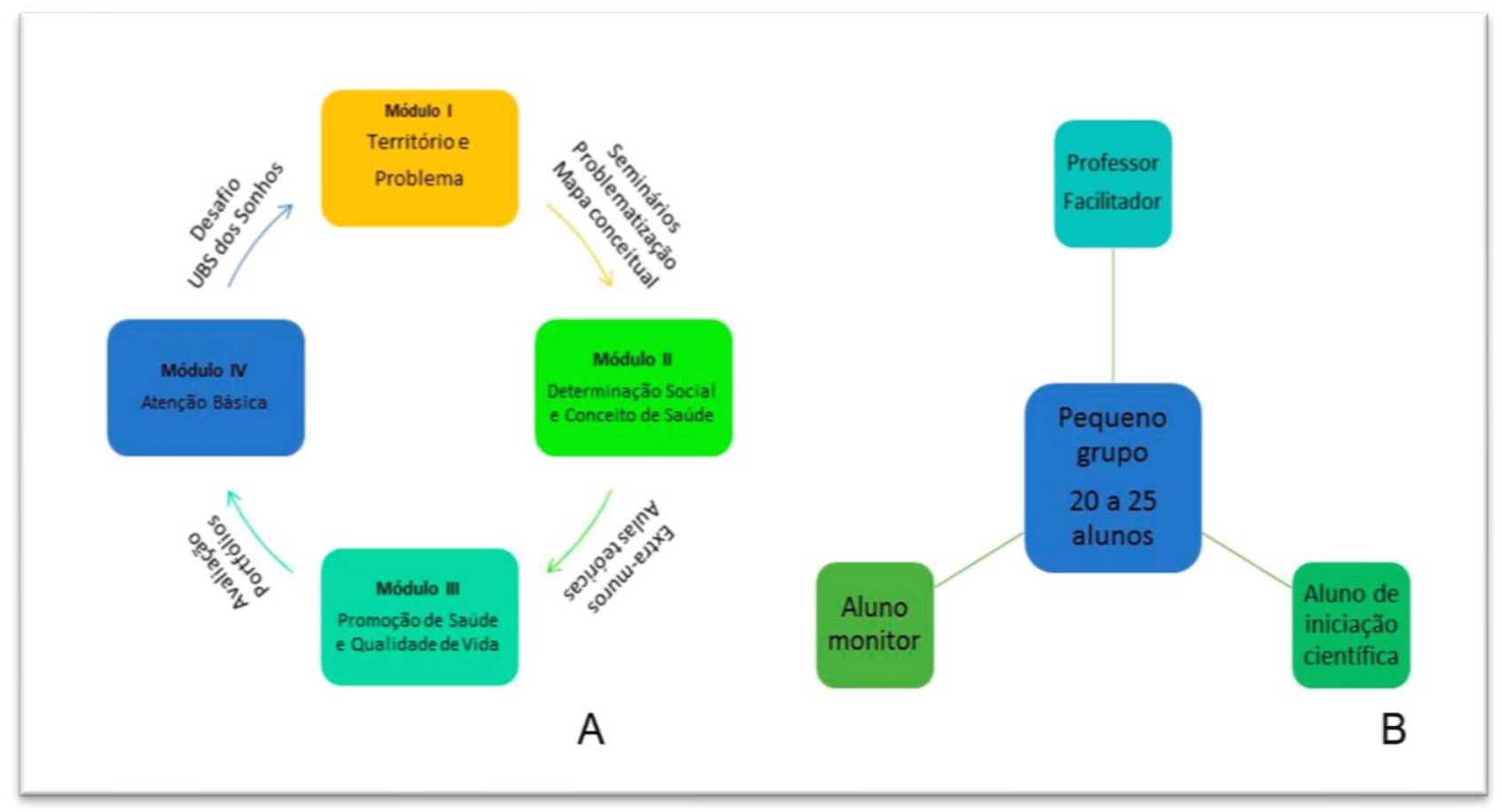

Figura 1. A, esquema dos pequenos grupos formados nas aulas de CAPS; B, fluxograma com identificação dos módulos e estratégias pedagógicas aplicadas na CAPS 
Tabela 1. Elementos pedagógicos finais explicitados a cada módulo e pactuados com os alunos para que possam ser trabalhados e apreendidos durante as aulas

\begin{tabular}{|c|c|}
\hline Módulo & Elementos pedagógicos finais \\
\hline Módulo I & $\begin{array}{l}\text { Conceito de território, conceito de problema, subjetividade e necessidade dos } \\
\text { problemas, setor saúde se organiza na lógica do território, território vivo }\end{array}$ \\
\hline Módulo II & $\begin{array}{l}\text { Determinação social do processo saúde doença, conceito ampliado de saúde, território } \\
\text { e suas relações com a determinação social }\end{array}$ \\
\hline Módulo III & $\begin{array}{l}\text { Promoção de saúde, Prevenção de agravos, Intersetorialidade, Qualidade de Vida, } \\
\text { Ações de promoção e prevenção no território, ações e espaços promotores de saúde, } \\
\text { políticas corretoras de desigualdades }\end{array}$ \\
\hline Módulo IV & $\begin{array}{l}\text { Atenção primária à saúde, Cuidado em Saúde, Equipe de Saúde, O trabalho em } \\
\text { equipe, UBS e o território }\end{array}$ \\
\hline
\end{tabular}

Como referencial pedagógico, aplica-se o arco de Maguerez ${ }^{14}$, a fim de trazer a problematização como ferramenta facilitadora do processo ensino-aprendizagem. A CAPS é organizada de modo que haja momentos de reflexão teórica, organização e apresentação de seminários e consolidação dos aprendizados por meio das visitas extramuros, que acontecem nas Unidades Básicas de Saúde (UBS) e nas suas áreas de abrangência (figura 1A).

Para viabilizar as atividades extramuros, ou visitas ao território, a equipe conta com apoio da Secretaria Municipal de Saúde de São Paulo e com uma parceria muito bem estabelecida e fundamentada com as UBS do entorno da instituição. A disciplina é organizada para que cada grupo fique na mesma área de abrangência das UBS ao longo de todo o ano. Essa estratégia faz com que os estudantes se apropriem do território, planejem previamente suas atividades e troquem as informações sobre as diferentes realidades encontradas com os outros grupos nas aulas de retorno dos extra-muros, quando fazemos as sínteses dos aprendizados e cada grupo prepara uma apresentação e divide seus achados, realizando esta dinâmica de dois em dois grupos.

Para gerenciar a disciplina também utilizase a estratégia dos Ambientes Virtuais de
Aprendizagem (AVA), por meio da plataforma do Moodle $^{\circledR}$. Essa ferramenta proporciona a interface entre a equipe de professores e os estudantes. O espaço é utilizado para disonibilização de material teórico, entrega dos produtos elaborados pelos estudantes ao longo da disciplina, comunicação com equipe e fóruns de discussão. Também são utilizadas metodologias ativas para estimular a sedimentação da aprendizagem significativa, na perspectiva do ensino que liberta, que faz sentido ao educando e ensina o educando a "aprender a aprender ${ }^{15,16}$.

Após apresentar este panorama geral da organização da CAPS, descreveremos cada módulo, estratégias pedagógicas, roteiros das atividades extramuros, referenciais teóricos utilizados e desenvolvimento geral do módulo.

\section{Módulos da CAPS}

No primeiro módulo os estudantes reconhecem o território e seus problemas. Após a leitura e discussão de textos que tratam o conceito de território $^{17,18,}$, suas relações com a saúde ${ }^{19}$ e que problema tem íntima relação com a necessidade de quem vive o problema ${ }^{20}$, os estudantes fazem a primeira visita técnica ao território adscrito de uma UBS (por ano são visitados seis territórios diferentes, todos da coordenadoria oeste da Secretaria Municipal de Saúde. Dois roteiros 
complementares, com sugestões de itens para observação, são disponibilizados na plataforma Moodle (figura 2) e toda a visita é guiada por um agente comunitário de saúde (ACS) para cada grupo de 5 ou 6 estudantes. Portanto, cada pequeno grupo se divide nas microáreas do território de acordo com o local de atuação de seu ACS. Ao retornarem das visitas os gruos apresentam uma síntese do que foi aprendido. Uma aula de 20 a 30 minutos fecha o módulo e já abre o módulo seguinte, fazendo as ligações necessárias entre os elementos pedagógicos estudados.

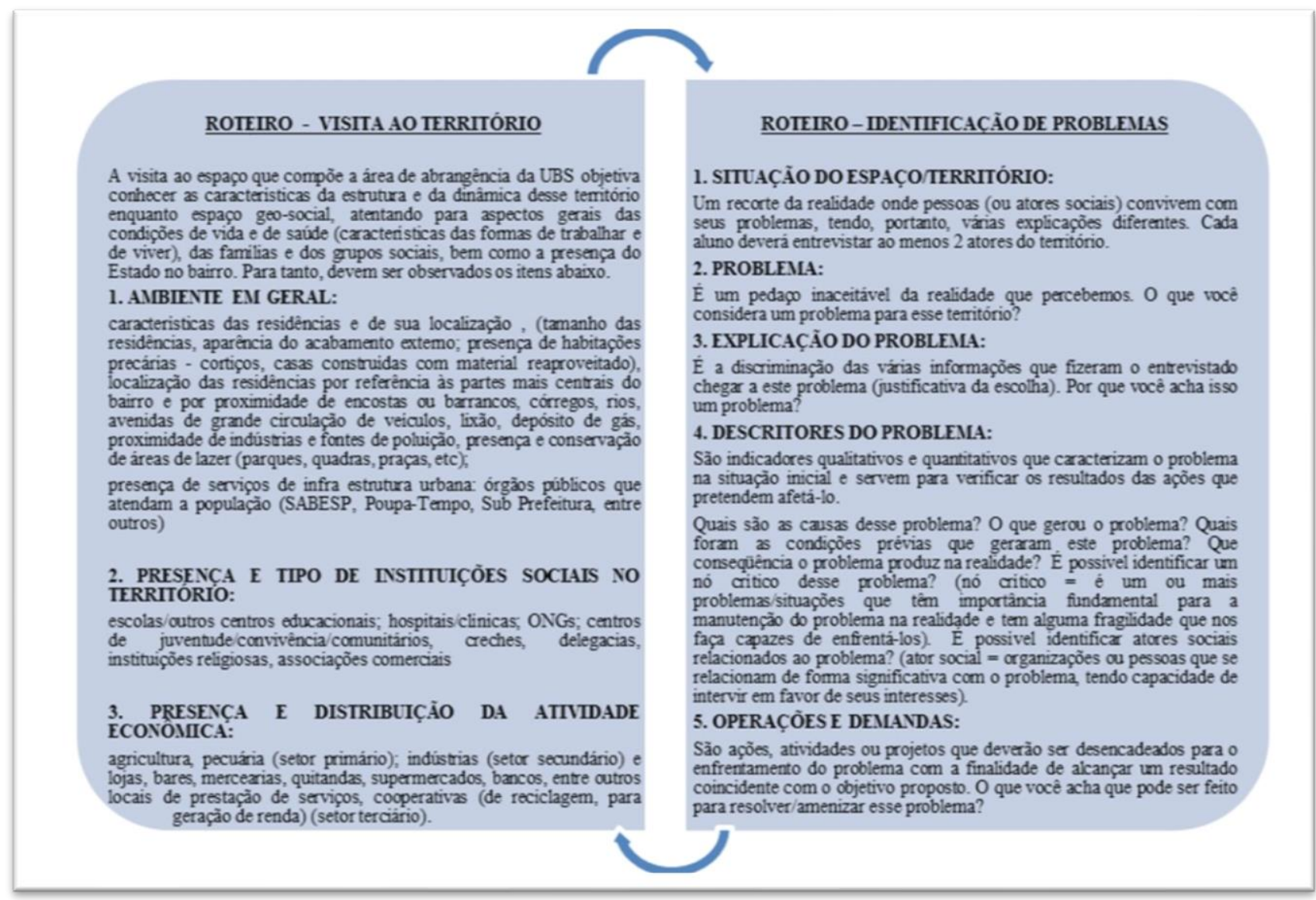

Figura 2: Roteiros "Visita ao território" e "Identificação de Problemas", disponibilizados no Sistema Moodle aos alunos para auxiliar na primeira vista ao território

No segundo módulo os temas abordados são a complexidade do processo saúde-doença ${ }^{21}$ e sua determinação social ${ }^{22}$. Após uma série de problematizações nos pequenos grupos, seminários preparados e apresentados pelos estudantes com base nos textos disponibilizados na plataforma Moodle ${ }^{23,24}$, uma nova visita é realizada, com auxílio dos mesmos ACS, que voltam nas suas microáreas para auxiliar os estudantes na identificação dos determinantes sociais de saúde com auxílio de um novo roteiro (figura 3). Após esta vista os estudantes voltam e constroem nos pequenos grupos um mapa conceitual $^{25}$, no qual apontam problemas, causas, efeitos, soluções para as realidades encontradas no território. Uma apresentação dos mapas e uma síntese são realizadas por uma das professoras que fecha o módulo e abre o módulo III, denominado "Promoção de saúde qualidade de vida". 
O terceiro módulo é um dos eixos estruturantes da CAPS, à medida que discute-se a ampliação da clínica à luz da promoção da saúde. Neste módulo são utilizadas algumas cartas de conferências e textos sobre promoção de saúde ${ }^{26,27}$, que trazem o aporte teórico e o caráter intersetorial das ações ${ }^{28,29}$. Discute-se, ainda, qualidade de vida e subjetividade ${ }^{30}$ e os desafios de promover um cuidado integral que garanta qualidade de vida ao usuário ${ }^{31}$. No território, durante a terceira visita, os estudantes procuram espaços promotores de saúde, compreendem como as pessoas utilizam aquele território nos seus momentos de lazer, de trabalho e de estudo. Conhecem, também por intermédio dos ACS, beneficiários de políticas corretoras de desigualdades e compreendem o impacto e dimensão dessas políticas na vida das pessoas. Um roteiro é disponibilizado no Moodle com algumas "missões" que os estudantes devem cumprir no território (figura 4). Volta-se do território e trocamse experiências e vivências, refazendo o mapa conceitual, já na perspectiva da intersetorialidade e da promoção da saúde. Discutese também as diferenças entre promoção de saúde e prevenção de agravos e os desafios para praticá-las.

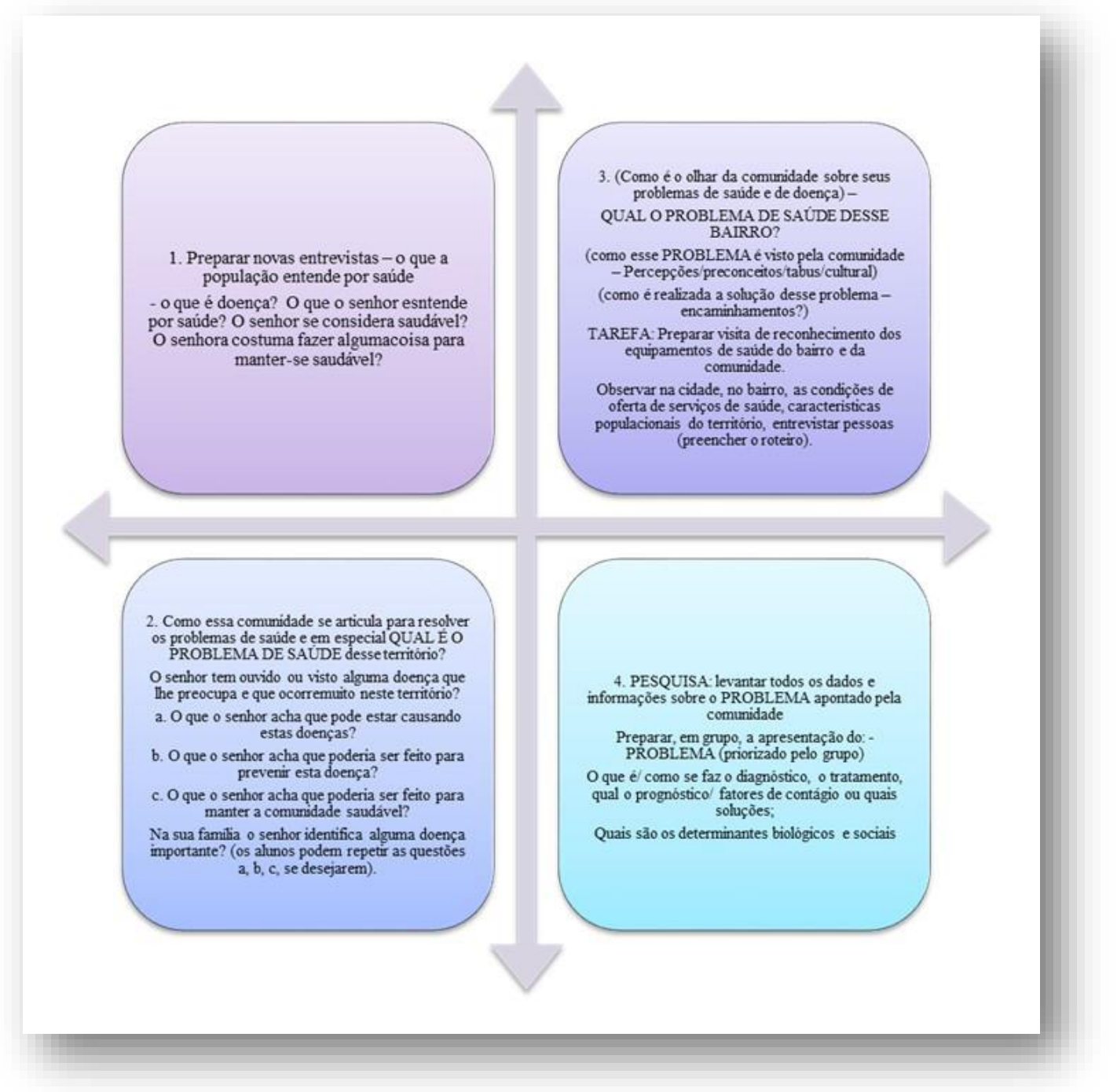

Fig ura 3. Esquema com os itens que constam do roteiro que norteia a segunda visita ao território 


\section{Roteiro III- Promoção de Saúde e Qualidade de vida}

Missão I: Identificar espaços promotores de saúde e diferenciá-los de ações de prevenção de agravos

Missão II: Identificar quais ações intersetoriais são realizadas com vistas à promoção de saúde. Como a comunidade percebe e recebe essas ações

Missão III: Qual a percepção do usuário sobre a sua qualidade de vida?

Missão IV: Identificar beneficiários das políticas públicas corretoras de desigualdades no território- Bolsa família, Minha casa minha vida, etc...

Figura 4. Roteiro da terceira visita ao território

Por fim, no último módulo, aborda-se o tema "atenção básica" e os estudantes, enfim, entram na UBS a fim de reconhecer as atividades desempenha- das pela equipe de saúde com a população adscrita ao território que visitaram durante o ano. Um roteiro também é disponibilizado no Moodle (figura 5).

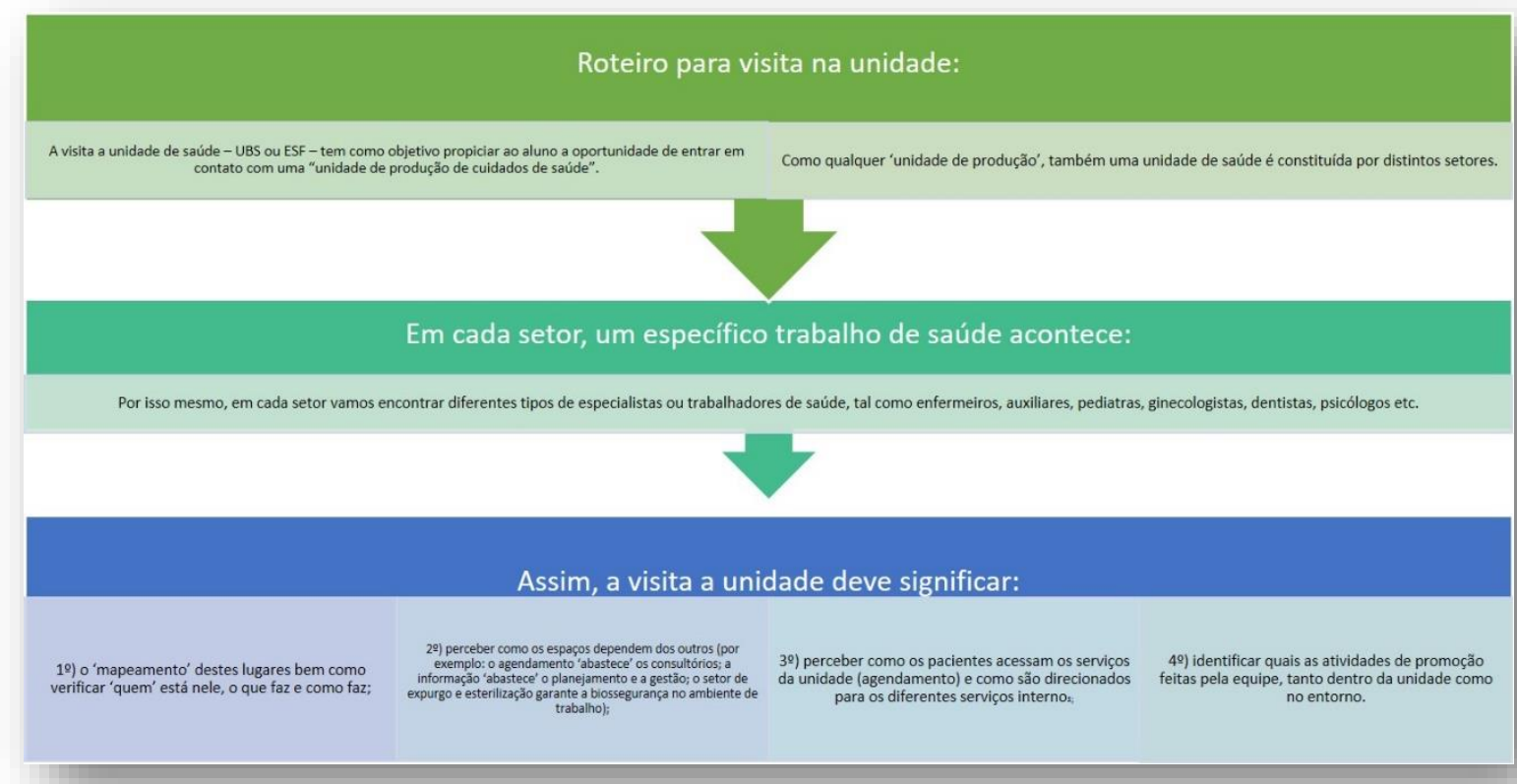

Figura 5. Roteiro da vista à Unidade Básica de Saúde - Módulo IV 
Intencionalmente esta é a última visita, à medida que o módulo de atenção básica reúne todos os conceitos trabalhados durante o ano. Sabe-se que a atenção básica tem na ESF eixo importante de organização e que a ESF está ancorada na lógica do território, tanto na organização das ações quanto no gerenciamento dos serviços, justificando o módulo I com muita clareza aos estudantes. Durante as aulas de atenção básica os estudantes percebem que toda a organização de território tem como eixo estruturante a determinação social do processo saúde doença e o cuidado em saúde preconizado na atenção basica $(\mathrm{AB})$ só é possível com base no modelo ampliado de saúde, assim como e estudado no módulo II. Os estudantes, ao entrarem na UBS, um dos lócus de cuidado da $\mathrm{AB}$, observam uma série de ações promotoras de saúde articuladas pela equipe de saúde, conselho gestor e usuários. Os murais da UBS são sempre uma grata surpresa aos estudantes que concretizam ações de promoção de saúde, contemplando assim os saberes do módulo III da disciplina. Os textos utilizados como referencial teórico para nortear as discussões e as atividades desse módulo tratam da $\mathrm{AB}$ como porta de entrada do sistema de saúde, como uma alternativa para se garantir níveis aceitáveis de saúde para todos, como responsável pela ordenação do cuidado ${ }^{30}$. Discute-se tecnologias de cuidado e que a $\mathrm{AB}$ se propõe a trabalhar tecnologias de relacionamento ${ }^{32,33}$. Reflete-se sobre os desafios de exercitar os princípios da atenção primária à saúde no contexto de alta especialização que vivemos atualmente e qual o papel da academia neste contexto, formando profissionais generalistas capazes de exercer a $\mathrm{AB}^{34,35}$. Todos esses textos também estão disponíveis no Moodle.

Após a visita final, como tarefa que fecha o curso e que pretende estabelecer uma dinâmica que articula todos os saberes e conceitos trabalhados durante $\mathrm{o}$ ano, propõe-se uma atividade em grupo denominada "Desafio UBS dos sonhos", na qual os estudantes devem criar uma UBS ideal, em um território específico, que atenda um determinado número de famílias definido pelo grupo. Este território deve ser caracterizado do ponto de vista econômico, social e político. Os estudantes devem descrever os equipamentos sociais e de saúde que compõem este território e os fluxos e fixos, descritos por Milton Santos (1996) ${ }^{36}$ que fazem deste território um espaço aonde a vida acontece. Agravos comuns enfrentados pelas equipes, podem ser descritos, áreas de maior vulnerabilidade social, estratégias de promoção, prevenção, cura e reabilitação podem ser descritas. A equipe de saúde bucal pode fazer parte da UBS, se o grupo desejar, e suas ações também podem ser descritas e discutidas. Os estudantes, após duas semanas de preparo da atividade, com ajuda dos professores e monitores apresentam para uma banca externa de convidados seus produtos e os melhores trabalhos vencem o "desafio". Os vencedores recebem um cerificado, normalmente o primeiro da faculdade, já que a CAPS é ministrada no primeiro ano. Esta atividade tem sido surpreendente e gerou na equipe o desejo de que eles pudessem carregar tudo que falaram e produziram naquele desafio ao longo do curso de Odontologia. Para tanto, registram-se em filmes as apresentações e estes são utilizado na Disciplina de Gestão e Planejamento, ministrada no ultimo ano.

\section{Sobre a avaliação}

O sistema de avaliação da disciplina possui três componentes: 1. Avaliação diária; 2. Extramuros; 3. Portfólios. A nota diária é atribuída pelo tutor do grupo levando-se em conta a participação do estudante nas atividades do dia. A nota de extramuros compõe $1 / 3$ da nota 
total do estudante, por entendermos que a experiência prática é fundamental na consolidação do aprendizado e esta experiência não pode ser substituída por qualquer outro tipo de tarefa. Aos estudantes do noturno esta atividade é oferecida durante o dia e já no manual no vestibular incluímos a informação de que algumas atividades obrigatórias seriam oferecidas durante o dia e que comprovantes de presença seriam fornecidos em caso de falta a emprego ou estágio. Em todos os anos da CAPS apenas um estudante não conseguiu fazer a atividade por não conseguir se ausentar do trabalho. Em todos os outros casos os estudantes conseguiram negociar reposições de horas trabalhadas e fizeram as atividades normalmente. O portfólio, elaborado individualmente pelo estudante, é o instrumento por meio do qual relata suas experiências e permite a reflexão sobre os temas abordados, além de possibilitar que os docentes acompanhem a evolução e a construção do conhecimento, sempre em consonância com os temas trabalhados. Suas postagens são feitas a cada final de módulo, via Moodle. Este processo de avaliação exige feedbacks constantes ${ }^{35}$ e este tem sido um grande desafio para nossa equipe. Espaços nos finais de algumas aulas são destinados a conversas individuais com os estudantes sobre seu percurso na disciplina e a pactuar como a equipe de professores poderia ajudar este educando no aprimoramento do processo de aprendizagem.

\section{A Clínica Ampliada como parte de um conjunto de disciplinas}

Uma única disciplina não é suficiente para romper paradigmas e garantir o ensino da Clínica Ampliada e da Saúde Coletiva, entretanto a CAPS é a primeira de uma série de disciplinas, tais como Ciências Sociais em Saúde e Metodologia Científica, também ministradas no primeiro ano, e Saúde Coletiva em Odontologia, ministrada no terceiro ano do curso. A Disciplina de Gestão e Planejamento, que é oferecida aos estudantes do último ano, mescla conceitos de saúde pública e iniciativa privada, além dos estágios vivenciais. É possível incluir ainda a Disciplina de Bioética, que no primeiro ano pauta temas importantes e que são retomados quando discutimos o cuidado ao ser humano. Portanto, esse é um caminho que se inicia na CAPS, mas que vai percorrer, de forma intencional, transversalmente, todo o currículo do estudante, na tentativa de consolidar e acrescentar novos saberes que contribuam para formação desejada. Esta formação é indicada nas DCN, a fim de que esses estudantes sejam estimulados para reconhecer as interfaces entre o biológico e o social do processo saúde doença, com vistas à promoção de saúde de indivíduos e das coletividades.

\section{CONSIDERAÇÕES FINAIS}

O modelo de disciplina apresentado é resultado de 10 anos de desenvolvimento do curso, que foi se alterando ao longo do período com base nas experiências de sala de aula e nas devolutivas da equipe de colaboradores e dos mais de 1300 estudantes que já cursaram a CAPS. Em 2017 foram iniciados os estágios vivenciais em algumas das UBS parceiras, como importante desdobramento da CAPS e da relação ensino-serviço que foi estabelecida por meio, também, da disciplina e de suas atividades cotidianas.

Neste percurso enfrentou-se desafios, pois como ocorre em diversas escolas de Odontologia, o curso tem uma característica predominantemente clínica, exigindo constantemente buscar estabelecer diálogo e demonstrar a importância das disciplinas do eixo social. Desde 2014 a FOUSP passa por um processo de reestruturação curricular para rever as alterações realizadas apartir do Pró-saúde e foi 
necessário muito esforço para manter as disciplinas do eixo citado como obrigatórias e com o número de créditos atual. $\mathrm{O}$ discurso contra-hegemômico, e a defesa do SUS podem ser temas polêmicos e o processo de diálogo e de convencimento precisa ser permanente.

Vale ressaltar que uma disciplina não é suficiente para romper paradigmas e garantir o ensino da clínica ampliada e da saúde coletiva, entretanto a CAPS é uma entre outras disciplinas que foram organizadas e planejadas ao longo do curso de Odontologia da FOUSP nesse sentido. Expor os estudantes à vivência no território tem sido muito importante para o desenvolvimento do curso e os relatos dos estudantes demonstram isso, entretanto, pesquisas precisam ser realizadas para que se entenda em profundidade os fenômenos envolvidos nos processos que ocorrem ao ao longo da disciplina com todos os atores envolvidos. $\mathrm{O}$ grupo tem desenvolvido pesquisas sobre o ensino da Clínica Ampliada com base no território e na determinação social do processo saúde doença, afim de produzir evidências que colaborem com o ensino médicoodontológico comprometido com cuidado integral, baseando as práticas no conceito ampliado de saúde. Ainda, trabalhos estão avaliando se os conteúdos trabalhados na CAPS estão permeando o cuidado na clínica odontológica, e este artigo pretendeu, de forma colaborativa, compartilhar o "passo a passo" de como realizamos o cotidiano da disciplina, esperamos que nossa experiência possa fomentar o debate em torno do tema.

\section{AGRADECIMENTO}

Os autores agradecem a colaboração, no cotidiano da disciplina, dos bolsistas de 2013 e 2014 dos programas Ensinar com Pesquisa ${ }^{\circledR}$, Aprender com Cultura e Extensão ${ }^{\circledR}$ e aos bolsistas de 2015 do programa Unificado ${ }^{\circledR}$, Aprender com Cultura e Extensão ${ }^{\circledR}$ e PEEG ${ }^{\circledR}$. Agradecemos à Universidade de São Paulo pelo fomento às pesquisas na área do ensino de graduação.

\section{ABSTRACT \\ The teaching of the Expanded Clinic for Dental course first-year students: an experience report} According to the National Curricular Guidelines for Dental courses, the training of the dentist should result in a professional capable of meeting the oral health needs of the population and be in line with the principles of the Unified Health System. The teaching of the clinic must extrapolate the operative act and broaden its scope of practice. Since 2006, the Faculty of Dentistry of the University of São Paulo teaches the students of the first semester of graduation the subject called Expanded Health Promotion Clinic. The Subject proposes to break with the health paradigm as the absence of disease and to present the interface between the biological and the social in this process, to the expansion of the clinic and integral care. This experience report aims to describe the subject, characterizing pedagogical strategies and their relevance in the insertion of students in the practice scenarios in primary care, as well as the evaluation methods implemented during the year. It is hoped that subject model presented may stimulate debate and promote discussions within the Subject courses so that as early as possible we can discuss the topics related to health care and the Extended Clinic.

Descriptors: Dental Education. Health Promotion. Curriculum.

\section{REFERÊNCIAS}

1. dos Santos BRM, Gonzales PS, de Almeida Carrer FC, de Araújo ME. Perfil e expectativas dos ingressantes da Faculdade de Odontologia da USP: uma visão integrada com as diretrizes curriculares nacionais e o sistema único de saúde. Rev ABENO. 2015;15(1), 28-37.

2. Brasil. Conselho Nacional de Educação. Diretrizes Curriculares Nacionais do curso de graduação em Odontologia. Resolução CNE/ 
CES 3/2002. Diário Oficial da União, Brasília, 04 mar. 2002.

3. Sette-de-Souza PH, da Silva ACB. Avaliações múltiplas para o aprendizado contínuo: relato deexperiência. Rev ABENO. 2016; 16(4):79-84.

4. Scavuzzi AIF, Gouveia CVD, Carcereri DL, Veeck EB, Ranali J, da Costa LJ, Morita MC, et al. Revisão das Diretrizes da ABENO para a definição de Estágio Supervisionado Curricular nos Cursos de Odontologia. Rev ABENO. 2016;15(3):109-13

5. de Araujo ME. Palavras e silêncios na educação superior em odontologia. Ciênc Saúde Coletiva. 2006;11(1), 179-82.

6. Kickbusch, I. Global health diplomacy: how foreign policy can influence health. Br Med J. 2011;342:d3154.

7. World Health Organization. Global strategy on human resources for health: workforce 2030. In: Global strategy on human resources for health: workforce 2030. 2016.

8. de Melo NB, Neto JDAF, de Vasconcelos Catão MHC, Bento PM. metodologia da problematização e aprendizagem baseada em problemas na Odontologia: análise bibliométrica dos trabalhos apresentados nas Reuniões da SBPqO. Rev ABENO. 2017; 17(2), 60-7.

9. Brasil. Ministério da Saúde. Secretaria de Gestão do Trabalho e da Educação na Saúde. Pró-Saúde: Programa Nacional de Reorientação da Formação Profissional em Saúde. Brasília, 2011. [Acesso em 20 ago. 2017]. Disponível em: http://prosaude.org Inot/prosaude-maio2009/proSaude.pdf.

10. Bozorgmehr K, Saint VA, Tinnemann P. O quadro de educação "saúde pública": um guia conceitual para monitoramento, avaliação e prática. Globalização e saúde. 2011;7(1):8, 2011.

11. Feuerwerker LCM. Além do discurso de mudança na educação médica: processos e resultados. São Paulo: Hucitec, 2002.

12. Ceccim RB, Feuerwerker LCM. O quadrilátero da formação para a área da saúde: ensino, gestão, atenção e controle social. Physis. 2004;14(1):41-65.

13. Universidade de São Paulo. Jupter, Sistema de Informação. Clínica Ampliada de Promoção de Saúde (2016). [Acesso em 20 ago. 2017]. Disponível em : http://uspdigital.usp.br/jupiterweb/obterDisc iplina?sgldis $=$ ODS0700\&verdis $=4$

14. Bordenave JD, Pereira AMP. Estratégias de ensino-aprendizagem. 25a ed. Rio de Janeiro: Vozes; 2004

15. Berbel NAN. A problematização e a aprendizagem baseada em problemas. Interface Comun Saúde Educ.1998;2:139-54.

16. Freire P. Pedagogia do oprimido. $17^{\mathrm{a}}$ ed. São Paulo: Paz e Terra; 1987.

17. Mendes R, Ausônia FD. Território: espaço social de construção de identidades e de políticas. SANARE. 2013; 4(1):39-42.

18. Santos M, Silveira ML O Brasil: território e sociedade no início do século XXI. Rio de Janeiro e São Paulo, Ed. Record, 2001.

19. Gondim GMM, Monken M, Rojas LI, Barcellos C, Peiter P. O território da saúde: a organização do sistema de saúde e a territorialização. Rio de Janeiro: Editora Fiocruz, 2008. p. 237-255.

20. Saviani D. Educacao brasileira: estrutura e sistema. A Filosofia na formacao do educador. Didata. 1997. 1:65-71,81-2.

21. Laurell AC. A saúde-doença como processo social. Rev Mex Cienc Pol Soc. 1976; 84: 131-57.

22. Buss PM, Pellegrini Filho A. A saúde e seus determinantes sociais. Physis. 2007;17(1): 77-93.

23. Batistella C. Saúde, doença e cuidado: complexidade teórica e necessidade 
histórica. O território e o processo. In. Fonseca AF, Corbo AMD. O território e o processo saúde-doença. Rio de Janeiro, EPSJV; FIOCRUZ, 2007. p.25-49.

24. Ferraz MSFC. O conceito de saúde. Rev Saúde Públ. 1997;31(5), 538-42.

25. Tavares R. Construindo mapas conceituais. Ciênc Cognição. 2007;(12):72-85.

26. Declaração de Alma-Ata. Conferência Internacional sobre cuidados primários de saúde; 6-12 de setembro 1978; Alma-Ata; USSR. In: Ministério da Saúde (BR). Secretaria de Políticas de Saúde. Projeto Promoção da Saúde. Declaração de AlmaAta; Carta de Ottawa; Declaração de Adelaide; Declaração de Sundsvall; Declaração de Santafé de Bogotá; Declaração de Jacarta; Rede de Megapaíses; Declaração do México. Brasília (DF): Ministério da Saúde; 2001. p. 15.

27. Carta de Ottawa. Primeira Conferência Internacional sobre promoção da saúde; novembro de 1986; Ottawa; Ca. In: Ministério da Saúde (BR). Secretaria de Políticas de Saúde. Projeto Promoção da Saúde. Declaração de Alma-Ata; Carta de Ottawa; Declaração de Adelaide; Declaração de Sundsvall; Declaração de Santafé de Bogotá; Declaração de Jacarta; Rede de Megapaíses; Declaração do México. Brasília (DF): Ministério da Saúde; 2001. p. 19.

28. Heidmann ITSB, Almeida MD, Boehs AE, Wosny ADM, Monticelli M. Promoção à saúde: trajetória histórica de suas concepções. Texto Contexto Enferm. 2006; 15(2), 352-8.

29. Westphal MF. Práticas intersetoriais nas políticas. Physis. 2012;22(4), 1333-56.
30. Minayo MCDS, Hartz ZMDA, Buss PM. Qualidade de vida e saúde: um debate necessário. Ciênc Saúde Coletiva. 2000; 5(1):7-18.

31. Botazzo, C. A bucalidade no contexto da Estratégia Saúde da Família: ajudando a promover saúde para indivíduos, grupos e famílias. In: Moysés ST, Kriger L, Moysés SJ (Org). Saúde bucal das famílias: trabalhando com evidências. São Paulo: Artes Médicas, 2008, p. 81-88.

32. Starfield B. Atenção Primária: equilíbrio entre necessidades de saúde, serviços e tecnologia. Brasília: Unesco/ Ministério da Saúde; 2002.

33. Gil CRR. Atenção primária, atenção básica e saúde da família: sinergias e singularidades do contexto brasileiro Primary health care, basic health care, and family health program: synergies and singularities. Cad Saúde Pública. 2006; 22(6): 1171-81.

34. Ayres JRCM. O cuidado, os modos de ser (do) humano e as práticas de saúde. Saúde Soc. 2004;13(3): 16-29.

35. Botazzo C. Sobre a Atenção Básica. Os cuidados primários de saúde no contexto da Reforma Sanitária Brasileira. Atenção básica no Sistema Único de Saúde: abordagem interdisciplinar para os serviços de saúde bucal. São Paulo: Páginas \& Letras, 2008, p. $1-12$.

36. Santos M. A natureza do espaço. São Paulo: Hucitec, 1996.

Correspondência para:

e-mail: fernandacsa@usp.br

Fernanda Campos de Almeida Carrer

Av. Professor Lineu Prestes, 2227

Cidade Universitária

05508-000 São Paulo/SP 